\title{
The Value of Transvaginal Ultrasonography in the Endometrial Evaluation of Breast Cancer Patients Using Tamoxifen
}

\author{
Talieh Kazerooni $^{\mathrm{a}} \quad$ Fariborz Ghaffarpasand $^{\mathrm{c}} \quad$ Ahmad Mosalaei $^{\mathrm{b}}$ \\ Yasaman Kazerooni ${ }^{\mathrm{a}}$ \\ Departments of ${ }^{\mathrm{a}}$ Obstetrics and Gynecology and ${ }^{\mathrm{b}}$ Nuclear Medicine and Radiotherapy, Shiraz University of \\ Medical Sciences, Shiraz, and 'Student Research Committee, Fasa University of Medical Sciences, Fasa, Iran
}

\section{Key Words}

Transvaginal ultrasonography $\cdot$ Tamoxifen $\cdot$ Breast cancer $\cdot$ Endometrial biopsy $\cdot$ Endometrial atrophy

\begin{abstract}
Objective: To estimate the value of transvaginal ultrasonography (TVU) in evaluating the endometrium in breast cancer patients on tamoxifen, and to investigate the relationship between TVU and histologic endometrial findings in these patients. Subjects and Methods: 107 breast cancer patients taking tamoxifen were included in this study. TVU was performed twice for each patient: prior to starting tamoxifen therapy and 1 year after taking tamoxifen. An endometrial thickness of $\geq 5 \mathrm{~mm}$ was considered abnormal. Endometrial biopsy was performed at the same time the 2nd TVU was done. The patients were divided into 2 groups: symptomatic (group A) and asymptomatic (group B), based on whether or not there was abnormal vaginal bleeding. Results: 31 patients (29\%) were symptomatic, while the remaining 76 (71\%) were asymptomatic. The endometrial thickness increased after 1 year of taking tamoxifen from $4.84 \pm 0.4 \mathrm{~mm}$ to 6.34 $\pm 2.1 \mathrm{~mm}$ in group $A$ and from $4.73 \pm 0.3 \mathrm{~mm}$ to $5.67 \pm 1.95$ $\mathrm{mm}$ in group $B(p>0.05)$. Endometrial biopsy revealed 77 (71.96\%) atrophic endometria and 21 (19.62\%) polyps. A comparison between the 2 groups showed a significant dif-
\end{abstract}

ference in patients with endometrial atrophy and atypical hyperplasia. Patients who had an endometrial thickness of $>5 \mathrm{~mm}$ had a significantly higher prevalence of atypical hyperplasia $(p=0.003)$ and polyps $(p=0.041)$. The sensitivity, specificity, positive predictive and negative predictive values of TVU were $63.3,28.57,25.67$ and $66.66 \%$, respectively. Conclusion: Our study showed a discrepancy between TVU and endometrial biopsy findings, due to the specific histology of the endometrium in breast cancer patients using tamoxifen. Due to this discrepancy, TVU alone is not an effective screening test for endometrial pathology and its application alone might lead to an undesirably high frequency of invasive diagnostic procedures.

Copyright $\odot 2010$ S. Karger AG, Basel

\section{Introduction}

The nonsteroidal antiestrogen tamoxifen has been shown to be a very effective drug in the adjuvant treatment of hormone-sensitive invasive [1] and noninvasive [2] breast cancer. Moreover, data from the National Surgical Adjuvant Breast and Bowel Project P1 Study [3] support the effectiveness of tamoxifen in the reduction of the risk of breast cancer in high-risk individuals. In October 1998, tamoxifen was approved for this indication in the

\section{KARGER \\ Fax +41613061234 \\ E-Mail karger@karger.ch}

www.karger.com
(C) 2010 S. Karger AG, Basel

1011-7571/10/0193-0222\$26.00/0

Accessible online at:

www.karger.com/mpp
Fariborz Ghaffarpasand

103, Biat Alley, Shuride Shirazi Street

PO Box 7173646199, Shiraz, Fars (Iran)

Tel. +98 917309 5214, Fax +98 7116483561

E-Mail fariborz_ghaffarpasand@yahoo.com 
United States. However, tamoxifen has estrogenic side effects in different organs. One of these estrogen-like side effects results in endometrial proliferation together with the possibility of a development of polyps, hyperplasia and a 2-4 times higher risk of endometrial cancer compared to postmenopausal women not taking tamoxifen $[3,4]$.

Transvaginal ultrasonography (TVU) is a well-established method for measuring endometrial thickness in otherwise healthy women with postmenopausal bleeding [5]. Most researchers recommend a cutoff value for the thickness of the endometrial double layer of $4-5 \mathrm{~mm}$. Below this value, the risk of endometrial carcinoma is negligible [6]. In asymptomatic postmenopausal women, TVU has not been adequately evaluated as a screening tool for endometrial cancer [7].

In postmenopausal patients with breast cancer, tamoxifen treatment is frequently associated with the presence of an increased endometrial thickness on TVU, often with an abnormal sonographic appearance of irregular echogenicity suspicious for polyps, hyperplasia, or carcinoma [8]. Investigators have, however, noted a discordance between sonographic and hysteroscopic and histologic endometrial findings in $45-90 \%$ of these patients [9]. The previously described cutoff value for endometrial thickness in postmenopausal women does not seem to apply to this group. Several authors have, nevertheless, recommended annual screening for endometrial pathology in tamoxifen-treated breast cancer patients with TVU using the standard cutoff criteria $[8,9]$. Therefore, the present study was performed to analyze the relationship between TVU and endometrial histology in breast cancer patients on tamoxifen.

\section{Subjects and Methods}

A prospective cohort observational study was performed from December 2004 through December 2006 in the Shiraz University Outpatient Clinics, Shiraz, Iran. 107 consecutive postmenopausal breast cancer patients were enrolled in this study. The detailed characteristics of the study population are listed in table $1.62 \mathrm{pa}-$ tients had a moderate income and 33 primary school education. 22 were smokers and 89 were married. 24 had a history of breast cancer in first-degree family members. The tumor was right-sided in 56 patients; in 49, the tumor size was between 2 and $5 \mathrm{~cm}$, and the tumor was moderately differentiated in 58 patients. In 36 patients, metastasis was mostly to the lungs. The study was approved by the Shiraz University of Medical Sciences Ethics Committee. Breast cancer patients taking tamoxifen who had been amenorrheic at least for 1 year and had estradiol levels of less than $0.10 \mathrm{nmol} / \mathrm{l}$ were included. Exclusion criteria were a history of endometrial pathologies including cancer or hyperplasia, a prior
Table 1. Characteristics of 107 postmenopausal breast cancer patients receiving tamoxifen

Frequency

\begin{tabular}{|c|c|}
\hline \multicolumn{2}{|l|}{ Income } \\
\hline Low & $39(36.4 \%)$ \\
\hline Moderate & $62(57.9 \%)$ \\
\hline High & $6(5.7 \%)$ \\
\hline \multicolumn{2}{|l|}{ Education } \\
\hline Illiterate & $30(28 \%)$ \\
\hline Primary school & $33(30.8 \%)$ \\
\hline High school & $25(23.3 \%)$ \\
\hline University & $19(17.9 \%)$ \\
\hline \multicolumn{2}{|l|}{ Smoking } \\
\hline Nonsmoker & $78(79.5 \%)$ \\
\hline Smoker & $22(20.5 \%)$ \\
\hline \multicolumn{2}{|l|}{ Marital status } \\
\hline Single & $9(8.4 \%)$ \\
\hline Married & $89(83.2 \%)$ \\
\hline Divorced or widowed & $9(8.4 \%)$ \\
\hline OCP use & $30(28 \%)$ \\
\hline Ethnicity (Fars) & $94(87.8 \%)$ \\
\hline History of BC in FDR & $24(22.4 \%)$ \\
\hline History of BC in SDR & $15(14.1 \%)$ \\
\hline \multicolumn{2}{|l|}{ Tumor side } \\
\hline Right & $56(52.3 \%)$ \\
\hline Left & $51(47.7 \%)$ \\
\hline \multicolumn{2}{|l|}{ Tumor size } \\
\hline$\leq 2 \mathrm{~cm}$ & $27(25.2 \%)$ \\
\hline $2-5 \mathrm{~cm}$ & $49(45.8 \%)$ \\
\hline$>5 \mathrm{~cm}$ & $21(19.6 \%)$ \\
\hline \multicolumn{2}{|l|}{ Tumor grade } \\
\hline Well-differentiated & $23(21.5 \%)$ \\
\hline Moderately-differentiated & $58(54.2 \%)$ \\
\hline Poorly-differentiated & $16(14.9 \%)$ \\
\hline Metastasis & $36(33.6 \%)$ \\
\hline
\end{tabular}

$\mathrm{OCP}=$ Oral contraceptive; $\mathrm{BC}=$ breast cancer; FDR = firstdegree relative; $\mathrm{SDR}=$ second-degree relative.

history of any gynecologic malignancy, an endometrial thickness of more than $5 \mathrm{~mm}$ at baseline TVU, a history of deep vein thrombosis, pulmonary emboli or pulmonary edema, collagen vascular diseases, thrombocytopenic (platelet count $<100,000 / \mu \mathrm{l}$ ) or leukopenic (white blood cell count $<4,000 / \mu \mathrm{l}$ ), and discontinuance of the treatment for any reason (developing side effects, lost to follow-up, etc.).

Endometrial thickness was defined as the width of the combined thickness of the anterior and posterior sides of the endometrium taken on a longitudinal plane using an ultrasound machine with a transvaginal probe of 5.0 MHz. The TVU was performed in lithotomy position with an empty bladder. In all patients, a routine TVU examination of the endometrium was performed twice: prior to starting tamoxifen treatment and 1 year after taking tamoxifen. Both baseline and follow-up ultrasonography were performed by the same gynecologist. All patients underwent an endometrial bi- 
opsy at the same time as when the second TVU was performed. Normal TVU values were considered to be $4-5 \mathrm{~mm}$ for the postmenopausal phase. The ultrasonic appearance of the endometrium was classified as normal ( $\leq 5 \mathrm{~mm})$, abnormal ( $>5 \mathrm{~mm})$, or suspicious for polyps. Sixteen patients who had abnormal baseline sonographic findings were evaluated by endometrial biopsy and excluded from the study. The performance characteristics were calculated with correlation to the endometrial histological findings. Neither the gynecologist nor the pathologist knew about the results. The patients were divided into symptomatic (group A) and asymptomatic (group B) groups, according to their positive or negative history of abnormal vaginal bleeding. The symptomatic patients (group A) were 31 with a mean age of $50.97 \pm 5.6$ years (range: 41-62 years), while the asymptomatic were 76 , with a mean age of $50.76 \pm 8.2$ years (range: $43-71$ years). The pathology of the endometrium was considered as the gold standard for the diagnosis of endometrium abnormalities. The sensitivity, specificity, positive predictive value and negative predictive value of TVU were calculated on the basis of pathologic reports.

Endometrial tissue was fixed in $10 \%$ buffered formalin and processed routinely for paraffin embedding. Three-micrometer sections were cut and stained with hematoxylin and eosin, and the slides were examined microscopically. The endometrial mucosa composed of epithelial glands as well as endometrial stromal fibroblasts, the epithelium and stroma were separately described by the pathologist. The histopathologic findings were divided into atrophy, atypical hyperplasia, simple hyperplasia, endometrial polyps with or without hyperplasia, and endometrial carcinoma [10]. An adequate sample was defined as 1 or more pieces of endometrium large enough to determine the gland-to-stroma ratio and endometrial morphological features, and an inadequate sample was defined as consisting only of blood or cervical mucus with fragments of benign endocervix, or a large amount of blood with only small fragments of endometrial glands and stroma [11].

\section{Statistical Analysis}

All statistical analyses were performed with the Statistical Package for Social Sciences version 13.0 (SPSS Inc., Chicago, Ill., USA). The results are expressed as mean value \pm standard deviation (SD). The $\chi^{2}$ test or Fisher's exact test was applied for comparison between frequencies. The independent-sample $t$ test was used to compare means between groups. Paired Student $t$ tests were used to compare the endometrial thickness before and after taking tamoxifen. All tests were two-sided. The level of significance was set at $\mathrm{p}<0.05$.

\section{Results}

The symptomatic patients (group A) were 31 (29\%) with a mean age of $50.97 \pm 5.6$ years (range: $41-62$ years), while the asymptomatic (group B) were 76 (71\%) with a mean age of $50.76 \pm 8.2$ years (range: $43-71$ years). The parity of most of the patients (34.6\%) was 4 (range: 2-7), with a mean of $4.38 \pm 1.1$ in group $\mathrm{A}$ and $4.17 \pm 1.3$ in group $B(p=0.419)$. The duration of the disease was 36.03 \pm 9.3 months in group A and $24.69 \pm 6.5$ months in
Table 2. Patients' characteristics in symptomatic and asymptomatic groups

\begin{tabular}{lrcr}
\hline & $\begin{array}{l}\text { Symptomatic } \\
\text { group (A) } \\
(\mathrm{n}=31)\end{array}$ & $\begin{array}{l}\text { Asymptom- } \\
\text { atic group (B) } \\
(\mathrm{n}=76)\end{array}$ & \\
\hline Age, years & $50.96 \pm 5.6$ & $50.76 \pm 8.2$ & 0.899 \\
Average parity & $4.38 \pm 1.1$ & $4.17 \pm 1.3$ & 0.419 \\
Duration of disease, months & $36.03 \pm 9.3$ & $24.69 \pm 6.5$ & 0.001 \\
End. thickness SON 1, mm & $4.84 \pm 0.4$ & $4.73 \pm 0.3$ & 0.393 \\
End. thickness SON 2, mm & $6.34 \pm 2.1$ & $5.67 \pm 1.95$ & 0.119 \\
\hline
\end{tabular}

Values denote means \pm SD. End. = Endometrial; SON $1=$ sonography before taking tamoxifen; SON 2 = sonography after 1 year of taking tamoxifen.

group $B(p=0.001)$. Prior to the tamoxifen treatment, the mean endometrial thickness for all the patients was 4.75 $\pm 0.4 \mathrm{~mm}$, while that of each group was $4.84 \pm 0.4 \mathrm{~mm}$ for group A and $4.73 \pm 0.3 \mathrm{~mm}$ for group B. After treatment, the overall endometrial thickness increased from $4.75 \pm 0.4 \mathrm{~mm}$ to $5.87 \pm 2.1 \mathrm{~mm}$ in 51 patients $(47.7 \%)$, and the difference was statistically significant $(\mathrm{p}<0.001)$. For group A it increased from $4.84 \pm 0.4 \mathrm{~mm}$ to $6.34 \pm$ $2.1 \mathrm{~mm}$, and for group B from $4.73 \pm 0.3 \mathrm{~mm}$ to $5.67 \pm$ $1.95 \mathrm{~mm}$. The mean age of the patients who had an endometrial thickness of more than $5 \mathrm{~mm}$ after 1 year of tamoxifen treatment (48.75 \pm 4.7 years) was significantly lower compared to those with an endometrial thickness of less than $5 \mathrm{~mm}(52.71 \pm 8.7$ years, $\mathrm{p}=0.006)$. The patients' characteristics in the symptomatic and asymptomatic groups are summarized in table 2 .

The findings of the pathology 12 months after tamoxifen therapy are given in table 3 . In both groups, atrophic endometria were found in 77 patients (71.96\%), atypical hyperplasia in $21(19.62 \%)$, polyps in 7 (6.54\%), hyperplastic polyps in $1(0.93 \%)$ and simple hyperplasia in 1 $(0.93 \%)$. No endometrial carcinoma was detected in any patient. Only patients with atrophy and atypical hyperplasia showed statistically significant differences between the symptomatic and asymptomatic patients (table 3 ). The pathologic findings in patients with and without evidence of abnormal endometrial thickening on ultrasound are given in table 4 . Approximately $70 \%$ of the significant changes consisted of benign polyps (table 4). Only patients with atypical hyperplasia and polyps showed a statistically significant difference between an endometrial thickness less than or greater than $5 \mathrm{~mm}$ (table 4). 
Table 3. Final pathologic diagnoses after 12 months of tamoxifen therapy in the symptomatic and asymptomatic patients

\begin{tabular}{lcccc}
\hline & $\begin{array}{l}\text { Symptomatic group (A) } \\
(\mathrm{n}=31)\end{array}$ & $\begin{array}{l}\text { Asymptomatic group (B) } \\
(\mathrm{n}=76)\end{array}$ & Total & $\begin{array}{l}\mathrm{p} \\
\text { (group A vs. B) }\end{array}$ \\
\hline Atrophy & $14(13.1 \%)$ & $63(58.8 \%)$ & $77(71.9 \%)$ & $<0.001$ \\
Atypical hyperplasia & $12(11.2 \%)$ & $9(8.5 \%)$ & $21(19.62 \%)$ & 0.002 \\
Polyps & $3(2.9 \%)$ & $4(3.7 \%)$ & $7(6.54 \%)$ & 0.327 \\
Hyperplastic polyps & $1(0.9 \%)$ & $0(0 \%)$ & $1(0.9 \%)$ & 0.291 \\
Simple hyperplasia & $1(0.9 \%)$ & $0(0 \%)$ & $1(0.9 \%)$ & 0.291 \\
Carcinoma & $0(0 \%)$ & $0(0 \%)$ & $0(0 \%)$ & - \\
Total & $31(29 \%)$ & $76(71 \%)$ & $107(100 \%)$ & \\
\hline
\end{tabular}

Table 4. Histologic findings in patients with normal and abnormal endometrial thickness 12 months after tamoxifen therapy

\begin{tabular}{lcccc}
\hline & $\begin{array}{l}\text { Endometrial thickness } \\
\leq 5 \mathrm{~mm}(\mathrm{n}=56)\end{array}$ & $\begin{array}{l}\text { Endometrial thickness } \\
>5 \mathrm{~mm}(\mathrm{n}=51)\end{array}$ & $\begin{array}{l}\text { Total } \\
(\mathrm{n}=107)\end{array}$ & $\mathrm{p}$ \\
\hline Atrophy & $45(42.1 \%)$ & $32(29.8 \%)$ & $77(71.9 \%)$ & 0.366 \\
Atypical hyperplasia & $7(6.5 \%)$ & $14(13.2 \%)$ & $21(19.7 \%)$ & 0.003 \\
Polyps & $3(2.9 \%)$ & $4(3.7 \%)$ & $7(6.6 \%)$ & 0.041 \\
Hyperplastic polyps & $1(0.9 \%)$ & $0(0 \%)$ & $1(0.9 \%)$ & 0.523 \\
Simple hyperplasia & $0(0 \%)$ & $1(0.9 \%)$ & $0.9 \%)$ & 0.477 \\
Carcinoma & $0(0 \%)$ & $0(0 \%)$ & $107(100 \%)$ & - \\
Total & $56(52.4 \%)$ & $51(47.6 \%)$ & $0.00 \%)$ \\
\hline
\end{tabular}

Of the 107 patients, 74 patients (69.1\%) had abnormal findings on the TVU examination, and 19 of the 74 patients had positive pathologic findings (positive predictive value $=25.67 \%$ ). Thirty-three patients showed normal findings on the TVU examination, and 22 of them had normal pathology (negative predictive value $=66.6 \%$ ). However, 11 of the 33 patients with normal TVU examinations had pathologic abnormalities. The sensitivity and specificity of TVU for predicting the endometrial pathology were 63.3 and $28.57 \%$, respectively. The false-negative cases included 9 atypical hyperplasias and 2 small polyps less than $5 \mathrm{~mm}$ in size. The 55 false-positive lesions demonstrated a focal thickening of the endometri$\mathrm{um}$, and they included 52 atrophic endometria, 2 endometrial polyps and 1 diffuse thickening.

\section{Discussion}

TVU has been the modality of choice for the evaluation of the endometrium during the last two decades; as such, it is widely used for a more thorough evaluation of endo- metrial lesions $[12,13]$. Some investigators have attempted to assess the diagnostic value of TVU examination by correlating and comparing it with pathologic and hysteroscopic findings [14]. In this study, tamoxifen therapy caused the endometrial thickness to increase significantly after one year. The respective sensitivity and specificity of 63.3 and $28.6 \%$ in predicting endometrial pathologies confirmed results of previous studies [15-17] that TVU is a poor diagnostic screening technique because of its high false-positive rate. Previous reports showed that the combination of TVU and hysteroscopic examination is a more accurate and cost-effective method than hysteroscopy with biopsy $[12,13]$. The sensitivity and specificity of hysteroscopic examination have been reported to be as high as $85-91$ and $83-100 \%$, respectively [12-14].

The short-term (one-year) tamoxifen therapy led to the development of endometrial pathologies that included atypical hyperplasia, polyps, hyperplastic polyps and simple hyperplasia; endometrial atrophy was most prevalent, probably due to our study population (all of them were postmenopausal). Further, none of our patients developed endometrial carcinoma, thereby indicating a 
high rate of benign endometrial lesions (28.1\%) and a low rate of malignant ones in short-course tamoxifen therapy. Equally, the explanation for the high rate of benign endometrial lesions and the small number of endometrial cancers in long-term tamoxifen users could be that most lesions, traditionally held as premalignant, rarely evolved into endometrial cancers. Furthermore, endometrial cancer is symptomatic at an early stage and is a rather slowly progressing malignancy with a high 5 -year survival [4]. Most reported cases of endometrial cancers in tamoxifen users are in women with abnormal vaginal bleeding. However, we could not find any malignancy in symptomatic patients. On the other hand, the prevalence of atypical hyperplasia was significantly higher in symptomatic patients, while atrophy was more common in asymptomatic ones. The prevalence of hyperplastic polyps and simple hyperplasia was higher in symptomatic patients, but the difference did not reach statistical significance. Although uncertainty remains as to whether or not all tamoxifen-related endometrial cancer cases have a low aggressive behavior, there is, as such, no evidence that the early detection and treatment of asymptomatic endometrial cancers may confer a survival advantage. Therefore, many clinicians question the need for general screening [18], basically because screening may do more harm than good in terms of unnecessary interventions, subsequent complications, increased cost and apparently being of no advantage to the patient. Hence, it is suggested that screening should be performed in those tamoxifen-taking patients who develop vaginal bleeding and in those who have preexisting endometrial pathologies [19]. Hence, the need to screen asymptomatic patients is not universally accepted. Much more importantly, because vaginal ultrasound scans give a great number of falsepositives, this could lead to the use of more aggressive and expensive procedures such as hysteroscopic-directed biopsy, whose cost/benefit ratio is not very favorable [20].

It has been shown that once the endometrium is abnormally thickened [16], TVU would probably be false-positive because of subendometrial vacuoles. In almost $50 \%$ of the cases of endometrial thickening, there are no intrauterine lesions and the endometrium is atrophic on further assessment. It has been suggested that the normal endometrial cutoff point ( $<5 \mathrm{~mm}$ in postmenopausal women) should be increased in women treated with tamoxifen, perhaps up to 8 or even $10 \mathrm{~mm}$, in view of the false-positive TVU findings [21]. However, also in these cases, the only way to obtain a correct diagnosis is to do additional tests such as hysteroscopies; endometrial blood flow studies are not helpful unless there is a clear vascular pedicle to a pol- yp. Doppler flow studies as an endometrial surveillance tool in women receiving tamoxifen therapy have been tested but the changes are not specific for endometrial pathology. Tamoxifen induces significant reductions in the impedance of blood flow in the endometrial and subendometrial vasculature regardless of the presence or absence of endometrial pathology. This is probably due to a dilatation of the existing vascular bed [22].

It has been shown that tamoxifen users are unlikely to develop endometrial hyperplasia or cancer during the first 3 years [19], hence it has been advised to do yearly follow-ups with TVU after year 3 [20]. A hysteroscopy will be required, but others advise screening if vaginal bleeding occurs [19]. The American College of Obstetricians and Gynecologists [23] recommends that women taking tamoxifen receive a yearly gynecological examination, education about the endometrial risks of tamoxifen, and encouragement to report promptly any vaginal bleeding, spotting, staining or leukorrhea. Our shortterm (one-year) follow-up of patients on tamoxifen therapy showed a development of endometrial hyperplasia and polyps which was statistically significant. Hence, we suggest a longer follow-up study.

Due to this discrepancy, TVU alone is not an effective screening test for endometrial pathology in these patients and its application results in an undesirably high frequency of invasive diagnostic procedures. Several groups report that the use of intrauterine saline infusion and subsequent TVU can enhance the differentiation between space-occupying lesions in the endometrial cavity such as endometrial polyps and other endometrial pathologies in patients who were diagnosed by TVU to have a thickened endometrium $[10,14,24]$.

\section{Conclusion}

TVU is a sensitive method to evaluate the endometrial cavitary lesions, but often this modality does not provide the physician with sufficient diagnostic information. With higher sensitivities, specificities, and positive and negative predictive values, endometrial biopsy can be better applied than TVU for evaluating breast cancer patients taking tamoxifen.

\section{Acknowledgment}

The authors wish to thank all the patients and their families who patiently participated in this study. 


\section{References}

$>1$ Osborne CK: Tamoxifen in the treatment of breast cancer. N Engl J Med 1998;339:16091618.

-2 Fisher B, Dignam J, Wolmark N, Wickerham DL, Fisher ER, Mamounas E, Smith R, Begovic M, Dimitrov NV, Margolese RG, Kardinal CG, Kavanah MT, Fehrenbacher L, Oishi RH: Tamoxifen in treatment of intraductal breast cancer: National Surgical Adjuvant Breast and Bowel Project B-24 randomised controlled trial. Lancet 1999;353: 1993-2000.

3 Fisher B, Costantino JP, Wickerham DL, Redmond CK, Kavanah M, Cronin WM, Vogel V, Robidoux A, Dimitrov N, Atkins J, Daly M, Wieand S, Tan-Chiu E, Ford L, Wolmark N: Tamoxifen for prevention of breast cancer: report of the National Surgical Adjuvant Breast and Bowel Project P-1 Study. J Natl Cancer Inst 1998;90:1371-1388.

4 Magriples U, Naftolin F, Schwartz PE, Carcangiu ML: High-grade endometrial carcinoma in tamoxifen-treated breast cancer patients. J Clin Oncol 1993;11:485-490.

$>5$ Goldstein SR, Nachtigall M, Snyder JR, Nachtigall L: Endometrial assessment by vaginal ultrasonography before endometrial sampling in patients with postmenopausal bleeding. Am J Obstet Gynecol 1990;163: 119-123.

6 Granberg S, Wikland M, Karlsson B, Norström A, Friberg LG: Endometrial thickness as measured by endovaginal ultrasonography for identifying endometrial abnormality. Am J Obstet Gynecol 1991;164:47-52.

7 Andolf E, Dahlander K, Aspenberg P: Ultrasonic thickness of the endometrium correlated to body weight in asymptomatic postmenopausal women. Obstet Gynecol 1993; 82:936-940.

-8 Exacoustos C, Zupi E, Cangi B, Chiaretti M, Arduini D, Romanini C: Endometrial evaluation in postmenopausal breast cancer patients receiving tamoxifen: an ultrasound, color flow Doppler, hysteroscopic and histological study. Ultrasound Obstet Gynecol 1995;6:435-442.
-9 Kedar RP, Bourne TH, Powles TJ, Collins WP, Ashley SE, Cosgrove DO, Campbell S: Effects of tamoxifen on uterus and ovaries of postmenopausal women in a randomized breast cancer prevention trial. Lancet 1994; 343:1318-1321.

10 Hendrickson MR, Kempson RL: Endometrial hyperplasia, metaplasia and carcinoma; in Fox H (ed): Obstetrical and Gynaecological Pathology. Edinburgh, Churchill Livingstone, 1987, pp 354-362.

11 Stovall TG, Ling FW, Morgan PL: A prospective, randomized comparison of the pipelle endometrial sampling device with the Novak curette. Am J Obstet Gynecol 1991;165: 1287-1289.

12 Saidi MH, Sadler RK, Theis VD, Akright BD, Farhart SA, Villanueva GR: Comparison of sonography, sonohysterography, and hysteroscopy for evaluation of abnormal uterine bleeding. J Ultrasound Med 1997;16:587591.

13 O’Connell LP, Fries MH, Zeringue E, Brehm W: Triage of abnormal postmenopausal bleeding: a comparison of endometrial biopsy and transvaginal sonohysterography versus fractional curettage with hysteroscopy. Am J Obstet Gynecol 1998;178:956-961.

14 Timmerman D, Deprest J, Bourne T, van den Berghe I, Collins WP, Vergote I: A randomized trial on the use of ultrasonography or office hysteroscopy for endometrial assessment in postmenopausal patients with breast cancer who were treated with tamoxifen. Am J Obstet Gynecol 1998;179:62-70.

15 Laifer-Narin S, Ragavendra N, Parmenter EK, Grant EG: False-normal appearance of the endometrium on conventional transvaginal sonography: comparison with saline hysterosonography. AJR Am J Roentgenol 2002;178:129-133.
16 Love CDB, Muir BB, Scrimgeour JB, Leonard RCF, Dillon P, Dixon JM: Investigation of endometrial abnormalities in asymptomatic women treated with tamoxifen and an evaluation of the role of endometrial screening. J Clin Oncol 1999;17:2050-2054.

17 Gerber B, Krause A, Müller H, Reimer T, Külz T, Makovitzky J, Kundt G, Friese K: Effects of adjuvant tamoxifen on the endometrium in postmenopausal women with breast cancer: a prospective long-term study using transvaginal ultrasound. J Clin Oncol 2000; 18:3464-3470.

18 Barakat RR: Screening for endometrial cancer in patients receiving tamoxifen for breast cancer. J Clin Oncol 1999;17:1967-1968.

19 Neven P, Vergote I: Tamoxifen, screening and new oestrogen receptor modulators. Best Prac Res Clin Obstet Gynaecol 2001;15: 365-380.

20 Machado F, Rodríguez JR, León JP, Rodríguez JR, Parrilla JJ, Abad L: Tamoxifen and endometrial cancer: is screening necessary? A review of the literature. Eur J Gynaecol Oncol 2005;26:257-265.

21 Lucente VR, Navarro NF, Dupree WB: The predictive value of endometrial thickness in patients receiving tamoxifen. J Pelvic Surg 2000;6:16-19.

22 Achiron R, Lipitz S, Sivan E, Goldenberg M, Horovitz A, Frenkel Y, Mashiach S: Changes mimicking endometrial neoplasia in tamoxifen-treated women with breast cancer: a transvaginal Doppler study. Ultrasound Obstet Gynecol 1995;6:116-120.

23 American College of Obstetricians and Gynaecologists: Tamoxifen and endometrial cancer. ACOG Committee Opinion 232. Washington, American College of Obstetricians and Gynaecologists, 2000.

24 Bourne TH, Lawton F, Leather A, Granberg S, Campbell S, Collins WP: Use of intracavity saline instillation and transvaginal ultrasonography to detect tamoxifen-associated endometrial polyps. Ultrasound Obstet Gynecol 1994;4:73-75. 